\title{
Crespo Fernández, Eliecer (ed.) (2018) Taboo in Discourse: Studies on Attenuation and Offence in Communication
}

BERNA

PETER LANG

ISBN 978-3-0343-3018-3

307 PÁGS.

La obra que reseñamos pretende ampliar el campo de estudio del tabú, yendo más allá de la visión tradicional que se centraba en una consideración exclusivamente léxica del fenómeno ${ }^{1}$, como apuntan Fernández Smith y Casas Gómez (pág. 27), y abarcando, por tanto, su uso en contextos comunicativos reales, en el ámbito de la pragmática y el análisis del discurso. Para ello, se presentan investigaciones que ofrecen diversas aproximaciones al análisis del tabú lingüistico, tanto desde el punto de vista de la atenuación (eufemismo) como de la ofensa (disfemismo), a los que el editor también alude como sweet talking y offensive talking, respectivamente (pág. 10).

Tal como refleja su propia etimología, la palabra tabú, procedente de las lenguas polinesias, significa "prohibido". Es mencionada por primera vez por el capitán Cook en 1777 para referirse a ciertas expresiones que los nativos preferian no mencionar explícitamente. Hoy en día, el tabú en el discurso, en palabras de Crespo Fernández, lejos de tratarse de una reliquia del pasado, está profundamente arraigado en la sociedad actual y afecta a la vida diaria, incluso en sociedades occidentales en las que la censura ha decrecido considerablemente (pág. 9).

A pesar de que el tabú tenga un carácter universal, las estrategias y técnicas empleadas para los usos eufemísticos y disfemísticos varian en las diferentes lenguas. Por ejemplo, mientras que en Italia es normal bestemmiare, es decir, ofender a Dios dirigiéndose a él con insultos como "perro", "sapo" o "cerdo", en España utilizamos, en este sentido, únicamente la expresión "Cagarse en Dios", reemplazado a veces por "Me cago en diez", algo también habitual en inglés, como en Oh my gosh en lugar de Oh my God, para evitar mencionar a Dios.

En lugar de como una simple técnica de sustitución léxica, en este volumen hallamos diversos trabajos que coinciden en su visión del tabú como una estrategia discursiva a la que el hablante puede recurrir - para la atenuación o la ofensa - en multitud de contextos comunicativos y diferentes tipos de discurso.

El libro se compone de un total de doce capítulos, el primero de los cuales ("Taboo in Discourse: An Overview") actúa a modo de introducción. En este, Crespo Fernández nos acerca al tabú en el discurso, entendido como "the prohibition of certain kinds of behaviour [...] believed to be harmful either for moral, religious, or social reasons" (pág. 9); es decir, como la prohibición de ciertos tipos de comportamiento que se consideran dañinos por razones

1 Todas las traducciones de esta reseña son propias. 
morales, religiosas o sociales, y que, desde un punto de vista lingüístico, incluiria todo aquello que resulta unmentionable. Las manifestaciones lingüísticas de este fenómeno pueden variar considerablemente ya no sólo entre lenguas, sino dependiendo también de la intención de los hablantes en las diferentes situaciones comunicativas, bien sea manteniendo la palabra tabú o bien atenuándola mediante eufemismos y el lenguaje politicamente correcto. Distingue, en este sentido, entre eufemismo (sweet talking), disfemismo (offensive talking), ortofemismo (straight talking), quasi-eufemismo y quasi-disfemismo, relacionándolos, a su vez, con la cortesía lingüística (Brown y Levinson, 1987), entendida como "concern for the feelings of the interlocutor(s) according to the norms of social behaviour, through the notion of face, i.e. one's public self-image" (pág. 10), o sea, la preocupación por los sentimientos de nuestro(s) interlocutor(es) según las normas de comportamiento social, para tratar de no dañar la imagen pública del otro. Dado que el fenómeno del tabú se relaciona con un gran número de temas y su consideración como tal puede variar con el tiempo y según el tipo de discurso, la intención del hablante y el contexto de uso, las diferentes aportaciones de Taboo in Discourse pretenden demostrar que se trata de algo mucho más complejo que una mera técnica de sustitución y requiere, en consecuencia, un análisis lingüístico, pero también social y cultural.

En el segundo capitulo ("From Lexicon to Discourse in the Linguistic Expression of Taboo: Configuring New Social Realities"), Fernández Smith y Casas Gómez insisten en la idea de que el tabú no se limita al nivel léxico de la lengua, sino que forma parte de la competencia comunicativa del hablante "by masking or hiding the negative aspects of reality, or directly covering that unpleasant reality itself" (pág. 25), mediante la estrategia pragmática de la atenuación, o bien "by exaggerating the positive aspects, or else the opponents' negative ones" (pág. 26), a través de la intensificación. Los autores se centran, en este caso, en el contexto de la comunicación pública, a partir del análisis de datos extraídos de la prensa escrita, donde las expresiones lingüísticas del tabú son presentadas como elementos altamente persuasivos a la hora de configurar nuevas realidades sociales.

Los siguientes cuatro capítulos ("Politically Tabooed Measures: Sanitizing the Economic Crisis through Metaphor and Euphemism", de Hellin Garcia; "Political Discourse in John Tutchin: Hedges as Euphemistic and Persuasive Devices", de López Campillo; "The Victim or the Cause? A Multimodal Critical Discourse Analysis of Cartoons Depicting PSOE's Internal Political Crisis", de de Muelas Gil, y "Offence Strategies in Political Cartoons", de Pinar Sanz) abordan los diferentes modos de mitigación y ofensa en el discurso político, aunque cada uno desde diferentes perspectivas, como la metáfora (Hellín Garcia), el empleo de ciertos mitigadores (López Campillo) o la atenuación y la ofensa por medio de la caricatura politica en la prensa (Muelas Gil y Pinar Sanz).

En cuanto a "Metonymy as a Strengthening Strategy in Road Safety Campaigns", de Negro Alousque, y "Pardon my Spanish: Attenuation of Taboo 
through Metapragmatic Euphemistic Formulae", de Pizarro Pedraza, analizan la utilización de fórmulas eufemísticas de disculpa (apology expressions), por ejemplo "Con perdón", como mecanismo de mitigación antes o después de una palabra o expresión tabú.

En "Please, Like Me: Coming Out of the Closet in the Millenial Generation", de López Cirugeda, y "Taboo in Prison: X-phemistic Language in Orange Is the New Black", de Sánchez Ruiz, las autoras llevan a cabo un estudio del discurso de dos series de televisión, con el fin de destacar el modo en el que se tratan ciertos temas tabú, como la homosexualidad y el lenguaje como arma en la cárcel, respectivamente.

Por último, tanto Martínez Mateo ("Approaching the Translation of Dysphemistic Language: Swear Words and Offensive Terms in The Catcher in the Rye") como Montero Cartelle ("The Discourse-Pragmatic Conditions of Sexual Interdiction in La Lozana. Masculine Sex and Escape from Vagueness") tratan el tema del sexo en dos obras literarias - novelas en ambos casos-: el primero de ellos a partir de la traducción al español de los términos ofensivos y los insultos de The Catcher in the Rye, de J. D. Salinger, y el segundo mediante la "vaguedad semántica" (semantic vagueness) característica de La lozana andaluza, una novela picaresca del siglo XVI escrita por Francisco Delicado.

En resumen, se trata sin duda de una obra muy completa, que puede resultar de utilidad para aquellos lectores interesados en una perspectiva multidisciplinar del fenómeno del tabú, que no se limite al nivel léxico de la lengua, sino que sea descrito desde un punto de vista más acorde con el ámbito de la pragmática y del análisis del discurso.

\section{REFERENCIAS}

BROWN, P. \& LEVINSON, S. (1987): Politeness. Some Universals in Language Use, Cambridge: Cambridge Unversity Press.

Alicia MaRIscal Ríos
Área de Lingüistica General
Instituto Universitario de Investigación en Lingüistica Aplicada
Universidad de Cádiz
Facultad de Filosofia y Letras
Avda. Dr. Gómez Ulla s/n
11003 Cádiz

Fecha de Recepción Fecha de Publicación
$29 / 11 / 2018$ $01 / 12 / 2018$
DOI: http:/ /dx.doi.org/ 10.25267/Pragmalinguistica.2018.i26.23 